\title{
Synthesis of Pd@Pt Core-shell Nanoparticles based on Photochemical Seed Growth Method and Co-reduction Method and the Electrocatalytic Performance
}

\author{
Shanshan $\mathrm{Li}^{1}$ Yingnan Dong ${ }^{1, a}$ Xiaoguo $\mathrm{Bi}^{1}$ Xudong $\mathrm{Liu}^{1}$ and Wei $\mathrm{Niu}^{1}$ \\ ${ }^{1}$ Shenyang Institute of Engineering, Shenyang 110136, China
}

\begin{abstract}
A series of Pd@Pt nanoparticles were synthesized based on electrochemical seed growth method and coreduction method in polyethylene-glycol and acetone solution system. The TEM/HR-TEM and XPS characterization proved that the prepared composite nanoparticles present core-shell structure and analyzed the chemical state of the particles. The electrocatalytic performance of Pd@Pt particles was studied by using the electrochemical workstation. The results showed that the Pd@Pt/C catalyst of different molar ratios of Pd to Pt exhibited preferable catalytic activity and stability for the methanol catalytic oxidation reaction. Among which, the Pd@Pt nanoparticles $(\mathrm{Pd}: \mathrm{Pt}=1: 1)$ prepared by co-reduction method, presented highest catalytic activity, which is 2 times higher than that of $\mathrm{Pt} / \mathrm{C}$ catalyst. The high catalytic activity produced by the core-shell structure was briefly discussed.
\end{abstract}

\section{Introduction}

The shortage of fossil fuel, and the atmosphere pollution and greenhouse effect caused by the usage of fossil fuel are problems need to be solved urgently in energy and environmental fields. Low-temperature fuel cells, including direct methanol fuel cell (DMFC) and proton exchange membrane fuel cell (PEMFC), exhibit an energy conversion rate as high as $60 \sim 80 \%$ and the actual service efficiency is $2 \sim 3$ times of that of common internal combustion engine. It is a green, energy saving and high efficient alternative energy which is applied widely. The research and development of low-temperature fuel cell have always focused on the search of electrode catalyst with high performance and the mechanism for improving the catalytic performance ${ }^{[1-3]}$.

Owing to the cheaper price of Pd than $\mathrm{Pt}$ and the widely applied catalytic activity, Pd has been introduced in the electrocatalysis of fuel cell recently. Y. H. Cho et $\mathrm{al}^{[4]}$ synthesized $\mathrm{PtPd}_{\text {alloy }} / \mathrm{C}$ PEMFC anode catalyst, which presented similar catalytic performance with $\mathrm{Pt} / \mathrm{C}$. But the atomic ratio of Pt to Pd was merely 1:19. Regarding core-shell catalyst, S.P. Jiang et a ${ }^{[5]}$ synthesized Pd@Pt core-shell nano-wire by adopting hard template electrochemical deposition method. The composite nanomaterial has large specific surface area and shows well catalytic activity for the methanol catalytic oxidation reaction (MOR). K. Sasaki et al ${ }^{[6]}$ conducted experiments in which single layer of $\mathrm{Cu}$ atoms were deposited on the surface of Pd particles of $4 \mathrm{~nm}$ in diameter; then the $\mathrm{Cu}$ atoms were replaced by $\mathrm{Pt}$ atoms (underpotential deposition method). Finally, they synthesized Pd@Pt

\footnotetext{
a Corresponding author: dyn4870@163.com
}

nanoparticles with $\mathrm{Pt}$ shell of single atom layer. The current density of Pt in unit mass for MOR is about 2.9 times of that of $\mathrm{Pt} / \mathrm{C}$. Generally, the research on $\mathrm{Pd}-\mathrm{Pt}$ catalyst is still in a fledging period; while the catalyst has shown its favourable cost advantage and application prospect.

Two novel methods for synthesizing Pd@Pt core-shell composite nanoparticles were presented based on the photochemistry. In the polyethylene-glycol (PEG)acetone solution system, the nanoparticles were synthesized by ultraviolet irradiation to reduce the mixture of Pd (II) and Pt (IV) ions simultaneously (coreduction method); regarding the seed growth method, $\mathrm{Pd}$ was applied as the crystal seed, and the Pt (IV) ions were irradiated by ultraviolet light to reduce and deposit on the surface of Pd seed. The characterization applying UV-Vis absorption spectra, TEM/HR-TEM and XPS verified that Pd@Pt core-shell composite nanoparticles with uniform size and monodispersion were obtained by employing the both methods. Furthermore, the size of the composite particles and the thickness of the Pt shell can be efficiently adjusted by changing the molar ratio of Pd (II) or Pd seed to Pt (IV). The average diameter of the composite nanoparticles synthesized adopting coreduction method is in the range of $4.1 \sim 2.9 \mathrm{~nm}$; and that using the seed growth method is in the range of 5.3 7.1 $\mathrm{nm}$.

Afterward, the obtained Pd@Pt nanoparticles were loaded on XC-72 carbon black, which was treated with $\mathrm{NaBH}_{4}$, to systematically study the activity for MOR. The research showed that the Pd@Pt core-shell composite nanoparticles present high catalytic activity for 
methanol. The authors considered that the high activity resulted from the promotion of $\mathrm{Pd}$ to $\mathrm{Pt}$.

\section{Experimental methods}

\subsection{Preparation of products}

Co-reduction: Certain amounts of PEG-400, acetone and different molar ratios of $\mathrm{H}_{2} \mathrm{PdCl}_{4}$ and $\mathrm{H}_{2} \mathrm{PtCl}_{6}$ (the molar ratios of $\mathrm{Pd}$ to $\mathrm{Pt}$ elements are $4: 1,1: 1$ and 1:4, respectively, and the total molar amount of noble metal is $\left.1.22 \times 10^{-5} \mathrm{~mol}\right)$. Then water was used to get the constant volume. After being mixed sufficiently, the solution was transferred into a quartz container and then exposed $4 \mathrm{~cm}$ away under ultraviolet light. UV-Vis spectra were recorded as time passed by until the spectral curve was the same as the previous one, which indicated that the reduction finished. The single $\mathrm{Pd}$ and $\mathrm{Pt}$ nanoparticles were prepared similarly.

Seed growth method: Certain amounts of Pd colloidal solution (crystal seed) and $\mathrm{H}_{2} \mathrm{PtCl}_{6}$ solution were added in the quartz container (the molar ratios of $\mathrm{Pd}$ to $\mathrm{Pt}$ are 4:1, 1:1 and 1:4, respectively; the total molar amount of noble metal does not change; and the total volume of the solution is still $50 \mathrm{~mL}$ ). After being mixed sufficiently, the quartz container was exposed $4 \mathrm{~cm}$ away under ultraviolet light until the reaction finished. All the reagents were analytical pure and the water was ultrapure.

\subsection{Characterization}

Images of the prepared nanoparticles were taken by transmission electron microscopy (TEM). The sample was prepared by dropping several drips of colloidal solution on carbon support film copper grid and dried at room temperature. Then the images were taken on H-800 TEM which operated at a voltage of $200 \mathrm{kV}$. By adopting lacey support film grid, HR-TEM detection was conducted, and the images were taken on Tecnai $\mathrm{G}^{2}$ F20 field emission TEM operated at a voltage of $200 \mathrm{kV}$. Meanwhile, XPS was performed on the sample as well. The obtained nanoparticles were loaded on XC-72 carbon black for electro-chemical measurements based on the method reported in literature ${ }^{[7]}$. The electro-chemical measurement was conducted at $30^{\circ} \mathrm{C}$, and three-electrode system was adopted with $\mathrm{Pt}$ as the counter electrode and SCE as reference electrode. The dissolved oxygen in the electrolyte was $0.5 \mathrm{~mol} \cdot \mathrm{L}^{-1} \mathrm{KOH}+2.0 \mathrm{~mol} \cdot \mathrm{L}^{-1} \mathrm{CH}_{3} \mathrm{OH}$. Before the measurement, high pure $\mathrm{N}_{2}$ was bubbled into the electrolyte to remove the dissolved oxygen and then $\mathrm{CV}$ curves were recorded in the $\mathrm{N}_{2}$ atmosphere. The measuring conditions are as follows: potential is in the range $-0.6 \sim 0.8 \mathrm{~V}$, potential scan rate is $50 \mathrm{mV} \cdot \mathrm{s}^{-1}$, and I-t curves are tested at electric potential of $-0.3 \mathrm{~V}$.

\section{Results and discussion}

\subsection{Characterization of Pd@Pt nanoparticles}

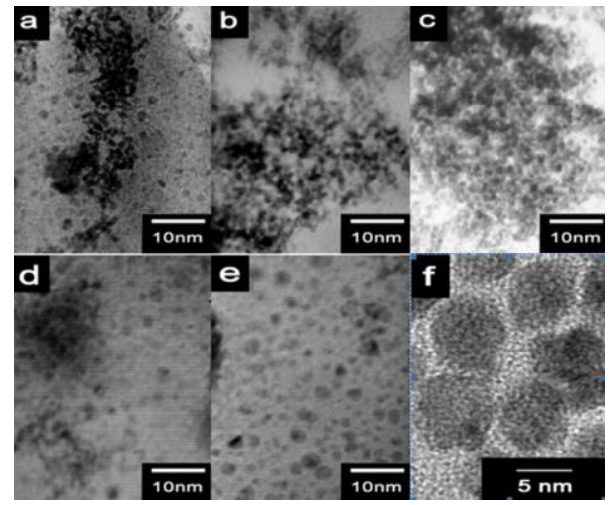

Figure 1. TEM and HR-TEM images of Pd core@Pt shell particles: $\mathrm{Pd}: \mathrm{Pt}=4: 1$ (a), 1:1 (b), 1:4(c) by coreduction; $P d: P t=4: 1$ (d), 1:1 (e), 1:4(f) by Pd seed growth.

The TEM/HR-TEM and XPS were adopted to characterize the Pd@Pt nanoparticles synthesized by the two methods. Figure 1 shows the TEM of Pd@Pt nanoparticles synthesized based on photochemistry. In the figure, most particles are spherical nanoparticles with uniform size and good dispersion. All the average diameters of bimetallic nanoparticles synthesized by seed growth method are larger than the diameter of Pd seed $(4.9 \mathrm{~nm})$ and increase from $5.3 \mathrm{~nm}$ to $7.1 \mathrm{~nm}$ with the increase of Pt proportion; while the average diameters of the bimetallic nanoparticles synthesized by co-reduction reduces as the addition of $\mathrm{Pt}$ increases, decreasing from $4.1 \mathrm{~nm}$ to $2.9 \mathrm{~nm}$. Figure $1 \mathrm{f}$ demonstrates the HR-TEM image of Pd@Pt core-shell composite particles which were prepared using seed growth method when $\mathrm{Pd}: \mathrm{Pt}=1: 4$. Lattice fringes are observed clearly in the spherical $\mathrm{Pd} @ \mathrm{Pt}$ composite particles with $7 \mathrm{~nm}$ in diameter, which indicates that the composite particles are nano-crystalline.

Table 1. Results of the XPS analysis of Pd@Pt particles.

\begin{tabular}{|c|c|c|c|c|c|c|c|}
\hline $\begin{array}{c}\text { Pd:Pt (molar } \\
\text { ratio) }\end{array}$ & $4: 1$ & $1: 1$ & $1: 4$ & $4: 1$ & $1: 1$ & $1: 4$ \\
\hline \multicolumn{2}{|c|}{$\begin{array}{c}\text { Synthetic } \\
\text { approach }\end{array}$} & \multicolumn{3}{|c|}{ Co-reduction } & \multicolumn{3}{|c|}{ Seed growth } \\
\hline \multirow{2}{*}{$\begin{array}{c}\text { Atom } \\
\text { ratio } \\
\text { on the }\end{array}$} & $\begin{array}{c}\mathrm{Pd} \\
\text { o }\end{array}$ & 70.6 & 40.0 & 2.1 & 70.4 & 40.2 & 3.4 \\
\cline { 2 - 8 } & $\begin{array}{c}\mathrm{Pt} \\
\text { surface }\end{array}$ & 29.4 & 60.0 & 97.9 & 29.6 & 59.8 & 96.6 \\
\hline
\end{tabular}

XPS as an important surface analysis technology shows the surface atomic concentration and the chemical state of the Pd@Pt nanoparticles. It provides strong evidence for determining the structure of the particles. So, XPS was performed for the Pd@Pt nanoparticles synthesized using the two methods (Figure 2). The results are listed in Table 1. It indicates that the $\mathrm{Pd} @ \mathrm{Pt}$ 
nanoparticles synthesized using co-reduction and seed growth method shows similar XPS analysis and the molar ratio of $\mathrm{Pd}$ to $\mathrm{Pt}$ on the particle surface is much less than that of Pd (0) or Pd (II) to Pt (IV) in the solution during preparation. It can be speculated that there is higher $\mathrm{Pt}$ atomic fraction in the surface structure, which indicates that the prepared $\mathrm{Pd} @ \mathrm{Pt}$ particles have core-shell composite structure. When $\mathrm{Pd}: \mathrm{Pt}=1: 4, \mathrm{Pd}$ element is hardly detected in the Pd@Pt core-shell nanoparticles synthesized by the both methods. This reveals that as the proportion of $\mathrm{Pt}$ increases, the $\mathrm{Pt}$ shell thickens continuously; in the condition, the Pt shell is too thick to make the inner Pd element be measured by XPS. In the linear fitting of the spectral lines of the samples in XPS energy spectrogram, two spectral peaks were observed in the $\mathrm{Pt} 4 \mathrm{f}$ and $\mathrm{Pd} 3 \mathrm{~d}$ electronic spectrogram. Compared with the energy spectrum of standard palladium ${ }^{[8]}$, the peak near $334 \mathrm{eV}$ is simple substance $\mathrm{Pd}\left(\mathrm{Pd} 3 \mathrm{~d}_{5 / 2}, 335.1\right.$ $\mathrm{eV})$, and that at $336 \mathrm{eV}$ around is oxidized $\mathrm{Pd}\left(\mathrm{PdO} 3 \mathrm{~d}_{5 / 2}\right.$, $336.3 \mathrm{eV})$. It demonstrates that the $\mathrm{Pt}$ and $\mathrm{Pd}$ atoms on the surface of the synthesized Pd@Pt core-shell composite particles are oxidized to a certain extent.
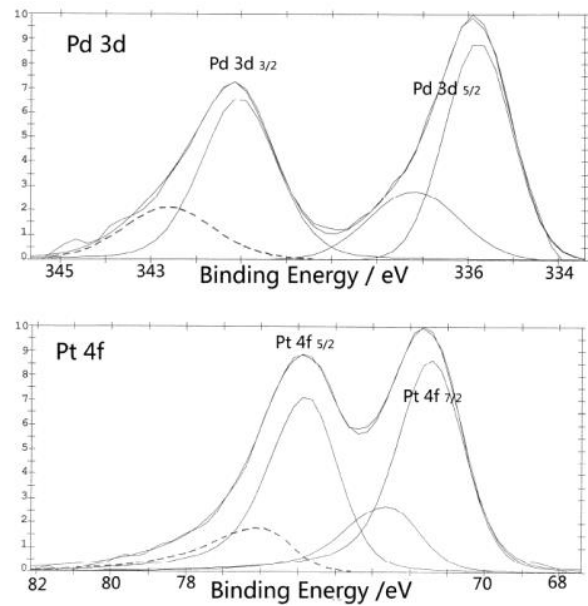

Figure 2. XPS spectra of $\mathrm{Pd} 3 \mathrm{~d}$ and $\mathrm{Pt} 4 \mathrm{f}$ of $\mathrm{Pd}$ core@Pt shell particles by co-reduction $(\mathrm{Pd}: \mathrm{Pt}=1: 1)$.

\subsection{MOR activity of Pd@Pt core-shell nanoparticles}

Figure 3 shows the cyclic voltammograms (CV) curves and time-current (I-t) curves of prepared $\mathrm{Pd} @ \mathrm{Pt} / \mathrm{C}$ and commercial catalyst $\mathrm{Pt} / \mathrm{C}$ (Johnson Matthey Company) for MOR in alkaline solution. Accordingly, the data of peak current density are listed in Table 2. The Pd@Pt core-shell nanoparticles synthesized using the two methods show high activity for MOR and similar activity law, that is, the activity at $\mathrm{Pd}: \mathrm{Pt}=1: 1$ is higher than that at $\mathrm{Pd}: \mathrm{Pt}=4: 1$ and $1: 4$. Additionally, the catalytic activity of Pd@Pt nanoparticles synthesized using co-reduction in $\mathrm{Pd}: \mathrm{Pt}=1: 1$ and $4: 1$ conditions is higher than that synthesized using seed growth method in the same conditions. The highest catalytic activity was achieved for Pd@Pt nanoparticles synthezied by co-reduction when $\mathrm{Pd}: \mathrm{Pt}=1: 1$. In the situation, the activity for MOR is
3 times of that of $\mathrm{Pt} / \mathrm{C}$ catalyst, while the cost is reduced by about $1 / 4$.
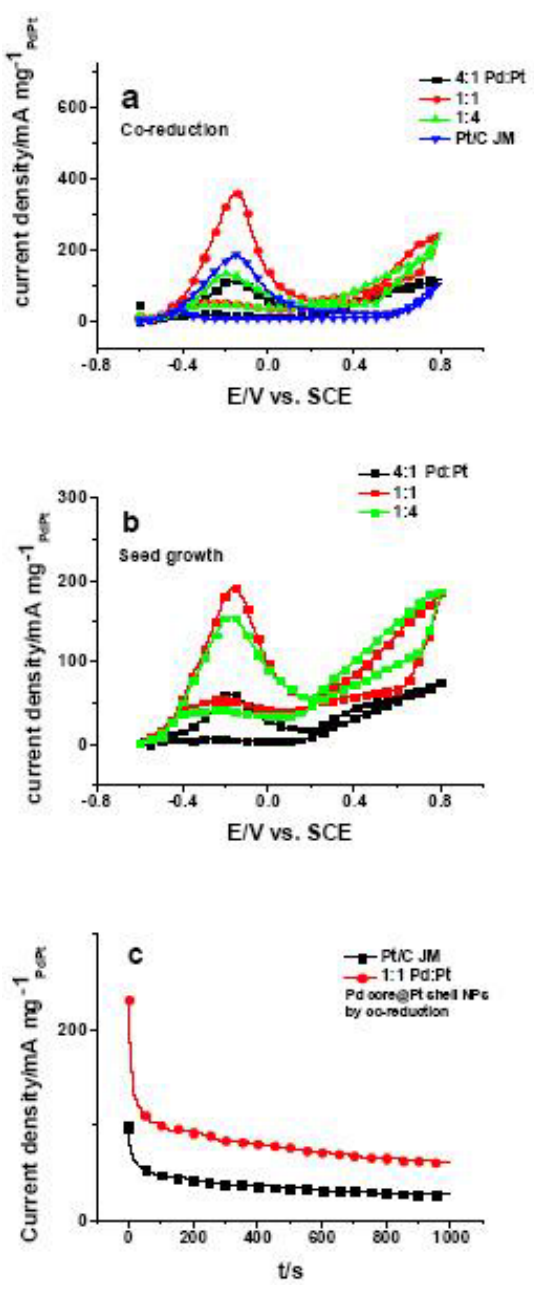

Figure 3. CV (a), (b) and I-t (c) of $\mathrm{Pd} @ \mathrm{Pt} / \mathrm{C}$ in 0.5 $\mathrm{mol} \cdot \mathrm{L}^{-1} \mathrm{KOH}+2.0 \mathrm{~mol} \cdot \mathrm{L}^{-1} \mathrm{CH}_{3} \mathrm{OH}$ solution

Table 2. Results of the electrochemical tests of Pd@Pt nanoparticles

\begin{tabular}{|c|c|c|c|c|c|c|c|}
\hline $\begin{array}{c}\text { Synthetic } \\
\text { approach }\end{array}$ & \multicolumn{3}{|c|}{ Co-reduction } & \multicolumn{3}{|c|}{ Seed growth } \\
\hline $\begin{array}{c}\text { Pd:Pt (molar } \\
\text { ratio) }\end{array}$ & $\begin{array}{c}\mathrm{Pt} / \mathrm{C} \\
(\mathrm{JM})\end{array}$ & $4: 1$ & $1: 1$ & $1: 4$ & $4: 1$ & $1: 1$ & $1: 4$ \\
\hline $\begin{array}{c}\text { Peak current } \\
\text { density of CV } \\
\left(\mathrm{Am} \cdot \mathrm{mg}^{-1} \text { PdPt }\right.\end{array}$ & 161 & 115 & 360 & 135 & 61 & 160 & 157 \\
\hline
\end{tabular}

According to the experiments, it is speculated that the $\mathrm{Pd}$ core promotes the catalytic activity of the synthesized $\mathrm{Pd} @ \mathrm{Pt}$ core-shell nanoparticles and the promotion is associated with the molar ratio of Pd to Pt. It is learned from the XPS analysis that the Pd in the Pd@Pt nanoparticles is prone to be oxidized. The oxidation products of $\mathrm{Pd}(\mathrm{PdO}$ and $\mathrm{PdOx})$ possibly promote the 
peeling of CO-like products which are generated during the reduction, therefore improving the catalytic activity of the composite nanoparticles ${ }^{[5]}$. On the other hand, the unique core-shell structure of $\mathrm{Pd} @ \mathrm{Pt}$ nanoparticles, which efficiently improves the utilization rate of $\mathrm{Pt}$, is likely the other reason for the catalytic activity improvement of $\mathrm{Pd} @ \mathrm{Pt} / \mathrm{C}$ core-shell catalyst. Owing to the smaller size and higher specific surface area of $\mathrm{Pt}$, the nanparticles prepared based on co-reduction method show better electrocatalytic activity than that synthesized by seed growth method. As to the underlying reason for the high activity of $\mathrm{Pd} @ \mathrm{Pt}$ core-shell composite nanoparticles, it is possibly related to the fine structure of the nanoparticles.

Figures 3c illustrate the I-t curves of $\mathrm{Pd} @ \mathrm{Pt} / \mathrm{C}$. In continuous working condition, $\mathrm{Pd} @ \mathrm{Pt} / \mathrm{C}$ core-shell catalyst $(\mathrm{Pd}: \mathrm{Pt}=1: 1$, Co-reduction $)$ exhibits similar stability to that of $\mathrm{Pt} / \mathrm{C}$.

\section{Conclusions}

(1) In PEG-acetone solution system, Pd@Pt core-shell composite nanoparticles with uniform size and good monodispersion were synthesized by photochemical reducing the mixture of Pd (II) and Pt (IV) ions or based on the Pd seed growth method with existence of Pt (IV). The size of the composite particles and the thickness of the Pt shell can be adjusted by changing the molar ratio of Pd (II) or Pd (0) to Pt (IV) ions. The average diameters of the obtained particles are in the ranges of 4.1 2.9 nm and 5.3 7.1 nm based on co-reduction and seed growth method, respectively. (2) XPS analysis reveals that the Pd@Pt nanoparticles synthesized by the two methods show core-shell structure. (3) Electrochemical analysis proved that all the synthesized Pd@Pt nanoparticles present high activity for MOR. The promotion of $\mathrm{Pd}$ core for Pt shell and the specific surface area of Pt increased by the core-shell structure are probably the main reasons for the high activity of $\mathrm{Pd} @ \mathrm{Pt}$ core-shell nanoparticles.

\section{Acknowledgements}

The work reported in this paper has received financial support from National Natural Science Foundation of China (No. 51164017 and 20863003).

\section{References}

1. X. D. Wang, X. F. Xie, M. Wang. Progress in Chemistry, 509, 23 (2011)

2. J. Liu, S. Z. Qiao, J. Song. ChemComm, 13658, (2011)

3. Y. N. Dong, S. S. Li, L. Cong. Yunnan Chemical Technology, 21, 39 (2012)

4. Y. H. Cho, B. Choi. Electrochem. Commun., 378, 9 (2007)

5. H. Wang, C. Xu, F. Cheng. Electrochem. Commun., 1575, 10 (2008)

6. K. Sasaki, J. X. Wang, H. Naohara. Electrochem. Acta., 2645, 55 (2010)

7. J. H. Zeng, J. Yang, J. Y. Lee. J. Phys. Chem. B, 24606, 110 (2006)
8. F. M. John. Handbook of X-Ray Photoelectron Spectroscopy (Perkin-Elmer Physical Electronics DiVision, 1992) 